\title{
0 enfoque CTS no curso de Pedagogia: problematizando o ensino de ciências nos anos iniciais do ensino fundamental
}

\author{
Focus on STS in the pedagogy teacher education: problematizing the science \\ education in the elementary school
}

Graziela Piccoli Richetti*

\section{Resumo}

\begin{abstract}
Nos cursos de Pedagogia, as discussões sobre o ensino de ciências (EC) geralmente são limitadas, pois, nos anos iniciais do ensino fundamental, priorizam-se a alfabetização e o ensino da matemática. Documentos curriculares recomendam que o EC contemple discussões sobre as interfaces entre ciência, tecnologia e sociedade (CTS), cujo enfoque pressupõe o desenvolvimento da alfabetização científica dos estudantes. Os docentes dos anos iniciais do ensino fundamental precisam estar preparados para planejar aulas e atividades que articulem temas de relevância social com significados reais. Apresentam-se, neste artigo, perspectivas do enfoque CTS para problematizar conteúdos de ciências dos anos iniciais do ensino fundamental no curso de licenciatura em Pedagogia. No componente curricular Fundamentos de Ciências, os licenciandos elaboraram sequências de atividades que deveriam articular um tema de relevância social aos pressupostos teóricos do enfoque CTS e aos conteúdos de ciências. As propostas priorizaram temas sobre meio ambiente e saúde, favorecendo a construção de ideias sobre aspectos sociais, culturais e tecnológicos, contribuindo para a formação da cidadania. Depreende-se que os cursos de licenciatura devem trazer as discussões sobre CTS em seus componentes curriculares, visando uma formação inicial de qualidade e que aborde situações cotidianas. Nessa perspectiva, o ensino de ciências poderá favorecer o desenvolvimento da alfabetização científica e o exercício da cidadania.
\end{abstract}

Palavras-chave: Alfabetização científica. CTS. Ensino de ciências. Estratégias metodológicas. Formação inicial de professores.

\section{Abstract}

The discussions about Science education (SE) in the pedagogy courses are usually limited, because literacy and mathematical learning are prioritized in the elementary school. Brazilian curricular documents recommend that the SE contemplate discussions about Science, Technology and Society (STS) whose approach presupposes the development of students' scientific literacy. Teachers who need to be prepared to plan classes and activities that articulate socioscientific themes with real meanings. This article presents perspectives with a focus on STS to problematizing science contents in pedagogy teacher education. In the curricular component of Science' fundamentals, the undergraduate students proposed activities that should articulate a socioscientific theme to the STS with the contents about Science. The proposed activities prioritized themes about environment and health, favoring the construction of ideas about social, cultural and technological aspects, contributing to formation of citizenship. It should be noted that undergraduate courses should bring the STS discussions into their curricular components, aiming for a quality teacher education that addresses everyday situations. In this perspective, SE may favor the development of scientific literacy and the exercise of citizenship.

Keywords: Scientific Literacy. STS. Science Education. Methodological strategies. Teacher education.

\author{
Recebido em 08/11/2017 - Aprovado em 10/02/2018 \\ http://dx.doi.org/10.5335/rep.v25i2.8165
}

Doutora em Educação Científica e Tecnológica pela Universidade Federal de Santa Catarina. Docente permanente no Programa de Pós-Graduação em Educação e professora de Química na Faculdade de Educação da Universidade Federal de Juiz de Fora, Minas Gerais. E-mail: grazielapr@gmail.com 


\section{Introdução}

Muitas das dificuldades enfrentadas pelos professores dos anos iniciais do ensino fundamental para ensinar ciências têm origem nos cursos de Pedagogia, cuja formação não se resume à docência na educação infantil, nos anos iniciais do ensino fundamental e na educação de jovens e adultos, mas abrange também a atuação em orientação, supervisão e administração escolar. As Diretrizes Curriculares Nacionais para o Curso de Graduação em Pedagogia (licenciatura) estabelecem que os componentes curriculares desses cursos contemplem os conhecimentos necessários às habilitações oferecidas, principalmente aqueles referentes a Língua Portuguesa, Matemática, Geografia, História, Ciências, Artes e Educação Física, presentes no currículo da escolarização básica (BRASIL, 2006). É uma formação docente generalista, que, para o ensino de ciências, acaba por se constituir um dos grandes obstáculos à atuação docente dos recém-formados.

Em estudo realizado no Brasil por Gatti e Nunes (2009) sobre a formação inicial de professores, as pesquisadoras constataram que os fundamentos teóricos são amplamente abordados nos componentes curriculares. Entretanto, os aspectos práticos são relegados, influenciando diretamente na atuação profissional após a formação, visto que os graduandos não receberam preparo suficiente para relacionar conteúdos disciplinares aos contextos de vida dos estudantes escolares e da sociedade em geral. Em estudo posterior, Gatti identificou resultados semelhantes e alertou que há certo idealismo nas proposições dos projetos pedagógicos dos cursos de licenciatura, porém, tais "[...] ideias não se concretizam na formação realmente oferecida, e teorias e práticas não se mostram integradas" $(2014$, p. 39).

No caso das ciências da natureza, a formação oferecida nos cursos de Pedagogia é precária, pois é "apenas um verniz superficial de formação pedagógica e de seus fundamentos que não pode ser considerado realmente uma formação de profissionais para atuar em escolas atualmente" (GATTI, 2014, p. 39). Isso se agrava porque a área de ciências ainda se mantém como um eixo interdisciplinar dos currículos escolares, o que deixa as licenciaturas com uma "[...] função social importante a cumprir: qualificar o professor de Ciências para o ensinar e o aprender Ciências Naturais como área interdisciplinar de conhecimento e saber se posicionar criticamente diante de seus produtos" (MALDANER; NONENMACHER; SANDRI, 2010, p. 113).

Nos cursos de Pedagogia, a carência de oportunidades para pensar e vivenciar estratégias didáticas para o ensino de ciências nos anos iniciais do ensino fundamental, associada às inexpressivas discussões dos fundamentos teóricos e metodológicos do ensino de ciências, pode resultar em atuações docentes que replicam as práticas tradicionais vivenciadas na graduação ou, ainda, na educação básica. 
Para os recém-formados em Pedagogia, configura-se uma situação preocupante, primeiramente pela necessidade de articular responsabilidades e (im)possibilidades anteriormente não vivenciadas. Depois, por terem vivenciado, durante a formação inicial, discussões pouco representativas sobre os processos, os conteúdos e as metodologias voltados ao ensino de ciências (GATTI, 2014; LIMA; MAUÉS, 2006). Nesse cenário carente de discussões articuladas entre os fundamentos teóricos e os práticos, o enfoque ${ }^{1}$ ciência, tecnologia e sociedade (CTS) apresenta-se como uma possibilidade para ensinar conteúdos de ciências menos fragmentados e mais integrados por meio de trabalhos interdisciplinares, favorecendo aos estudantes uma melhor compreensão do mundo e das inter-relações entre o conhecimento científico, a tecnologia e o meio social.

Neste artigo, apresentam-se algumas reflexões sobre o trabalho final realizado no componente curricular Fundamentos teórico-metodológicos e prática escolar em ciências, do curso de licenciatura em Pedagogia da Universidade Federal de Juiz de Fora (UFJF), em Minas Gerais. Para a elaboração do trabalho final, os licenciandos escolheram temas que possibilitassem a discussão das inter-relações entre ciência, tecnologia e sociedade, denominados temas CTS. Cada grupo propôs estratégias metodológicas para ensinar conteúdos de ciências para uma das séries dos anos iniciais do ensino fundamental. O objetivo principal foi oportunizar discussões sobre as possibilidades e limitações do enfoque CTS para o ensino de ciências dos anos iniciais e, em particular, as dificuldades encontradas pelos licenciandos para articular fundamentos teóricos e atividades práticas propostas nos trabalhos.

A análise desses trabalhos finais buscou responder o seguinte questionamento: quais as perspectivas da incorporação do enfoque CTS na formação inicial de licenciandos em Pedagogia para problematizar o ensino de ciências dos anos iniciais? No âmbito deste artigo, os objetivos são: a) analisar, nos trabalhos finais, os temas escolhidos quanto às possibilidades para o enfoque CTS; b) avaliar, nas atividades sugeridas pelas equipes, as articulações entre o enfoque CTS e os conteúdos de ciências; e c) avaliar as possibilidades das propostas das equipes quanto às finalidades da alfabetização científica.

O presente artigo está estruturado em oito seções. Na primeira, são apresentados alguns apontamentos sobre o ensino de ciências nos anos iniciais do ensino fundamental a partir dos documentos oficiais. A seguir, discorre-se brevemente sobre o enfoque CTS, norteador do planejamento do componente curricular e que ofereceu embasamento teórico para este trabalho. Ainda nessa seção, situam-se as finalidades da alfabetização científica como objetivo principal do enfoque CTS e que serviram de mote para a análise dos trabalhos finais elaborados pelos licen- 
ciandos ao final do semestre letivo do componente curricular. O percurso do componente curricular é apresentado brevemente para situar o leitor sobre a condução do trabalho final e, na sequência, apresenta-se a análise dos trabalhos produzidos pelos licenciandos. Finalmente, são apresentadas algumas reflexões sobre o alcance das discussões dos aspectos práticos associados ao enfoque CTS e as limitações identificados nos trabalhos.

\section{0 ensino de ciências nos anos iniciais do ensino fundamental: algumas observações}

As situações e as ações vivenciadas pelos estudantes desde o início de suas vidas se apresentam mediadas por nomes, explicações e conceitos que são fundamentais para o processo de ensino e aprendizagem. É nos anos iniciais do ensino fundamental que os estudantes são apresentados à disciplina de Ciências por meio dos livros didáticos e das exposições orais feitas pelo professor. Os conteúdos dessa disciplina pertencem às áreas específicas de Química, Física e Biologia, bem como, em alguns casos, de Geografia. A transposição desses conteúdos para os anos iniciais tem sido objeto de estudo de pesquisadores por diferentes razões, entre as quais: a) pela limitação do seu ensino a um processo de memorização de vocábulos próprios da linguagem científica; b) pelas concepções, geralmente equivocadas, que os professores possuem sobre a ciência e os conhecimentos científicos; e c) pela crença dos professores de que os alunos dos anos iniciais não têm condições de aprender ciências devido à complexidade dos conteúdos (LIMA; MAUÉS, 2006; ROSA; PEREZ; DRUM, 2007).

Muitas vezes, os conteúdos de ciências são abordados com pouca ou nenhuma relação com o cotidiano e os conhecimentos do senso comum dos estudantes. Essa falta de clareza pode se constituir um obstáculo à aprendizagem, e uma das formas de o professor minimizar esse distanciamento está em conhecer o que seus alunos já sabem para problematizar esse conhecimento e

[...] para aguçar as contradições e localizar as limitações desse conhecimento, quando cotejado com o conhecimento científico, com a finalidade de propiciar um distanciamento crítico do educando, ao se defrontar com o conhecimento que ele já possui, e, ao mesmo tempo, propiciar a alternativa de apreensão do conhecimento científico (DELIZOICOV; ANGOTTI; PERNAMBUCO, 2011, p. 199).

Procedendo dessa forma, o professor favorece aos alunos a compreensão sobre a importância e as limitações do senso comum, bem como sua relação com os conhecimentos científicos. Um dos pontos de destaque dos documentos curriculares 
de ciências dos anos iniciais do ensino fundamental sugere ao professor a adoção de estratégias didáticas que valorizem o diálogo didático em sala de aula, proporcionando aos estudantes a construção do conhecimento científico.

Desde a publicação dos Parâmetros Curriculares Nacionais (PCNs) em 1997, docentes da educação básica têm sido orientados para o desenvolvimento de competências que permitam aos educandos "compreender o mundo e atuar como indivíduo e como cidadão, utilizando conhecimentos de natureza científica e tecnológica" (BRASIL, 1997, p. 31). Passadas duas décadas, a Base Nacional Comum Curricular (BNCC) reforça a importância dessas competências e, em particular, as Ciências da Natureza devem estar comprometidas com o letramento científi$\mathrm{co}^{2}$ dos estudantes. A apropriação dos conhecimentos científicos deve auxiliá-los a compreender o mundo em que vivem, atuar e se posicionar diante das situações cotidianas, fundamentais ao exercício da cidadania (BRASIL, 2017).

Além dos saberes disciplinares das Ciências da Natureza, os PCNs recomendam que outras questões de grande importância devem ser tratadas, como a violência, a saúde, os recursos naturais e os preconceitos, constituindo temas transversais, relacionados às problemáticas sociais da atualidade. A transversalidade pressupõe a integração dos temas nas diferentes áreas do conhecimento e o tratamento das relações interpessoais na escola, com o propósito de desenvolver nos estudantes as aptidões necessárias para participar de discussões referentes à sua comunidade. No texto da BNCC, há assertivas que fortalecem essas ideias, em particular no tocante à necessidade de superação da fragmentação do conhecimento, enfatizada pelas diferentes disciplinas escolares, em prol da valorização do contexto no qual tais conhecimentos se encontram, bem como sua aplicação à realidade existencial dos estudantes, acrescentando que:

[...] cabe aos sistemas e redes de ensino, assim como às escolas, em suas respectivas esferas de autonomia e competência, incorporar aos currículos e às propostas pedagógicas a abordagem de temas contemporâneos que afetam a vida humana em escala local, regional e global, preferencialmente de forma transversal e integradora (BRASIL, 2017, p. 19).

É nessa perspectiva que Santos e Schnetzler (2010) consideram a importância de os estudantes possuírem informações básicas, tanto em ciência como em áreas afins, para que possam compreender os problemas da sua comunidade e atuar como cidadãos. A afirmativa dos autores para o ensino médio pode ser extensiva aos anos iniciais do ensino fundamental, pois, nessa etapa, o ensino de ciências constitui um primeiro passo para a alfabetização científica e possibilita o estabelecimento de vínculos entre os fenômenos naturais e socioculturais. A abordagem de assuntos relacionados à ciência e à tecnologia, que façam parte do cotidiano dos estudantes, bem como a realização de atividades que desenvolvam a observação, a discussão e a 
elaboração de desenhos e de pequenos textos podem estimular o aprendizado e o interesse pelas ciências desde o início da escolarização básica (BRASIL, 1997, 2017).

\section{0 enfoque CTS e a alfabetização científica: alguns elementos norteadores do estudo realizado no componente curricular}

A tendência de levar as discussões sobre CTS para contextos educacionais iniciou após a Segunda Guerra Mundial em países da Europa, América do Norte e Austrália, impulsionada pela iminência de formar o cidadão em ciência e tecnologia, algo que o ensino de ciências não conseguia dar conta naquela época (SANTOS; MORTIMER, 2002). Desde a década de 1970, essas discussões têm influenciado o ensino de ciências no Brasil em prol da "necessidade de ir mais além da habitual transmissão de conhecimentos científicos", buscando aproximá-los da "natureza da Ciência e à prática científica e, sobretudo, de enfatizar as relações Ciência-tecnologia-sociedade-ambiente", contribuindo para a formação de cidadãos (CACHAPUZ et al., 2005, p.23). Tais pressupostos também são sustentados por pesquisadores brasileiros, como Santos e Mortimer (2002), Milaré, Richetti e Pinho-Alves (2009), Santos e Schnetzler (2010) e Chrispino (2017), e no documento da recém-homologada BNCC (BRASIL, 2017).

No âmbito educacional, o enfoque CTS busca oferecer uma melhor compreensão da ciência e da tecnologia em seu contexto social, abordando suas implicações sociais, éticas, econômicas, políticas e ambientais. A compreensão da ciência como atividade humana, historicamente contextualizada, não linear e intimamente relacionada à tecnologia e às questões sociais, constitui o eixo norteador de propostas curriculares interdisciplinares. Nesse contexto, o ensino de ciências com enfoque CTS possibilitaria aos estudantes a aquisição de conhecimentos e habilidades fundamentais para o exercício da cidadania.

Um dos objetivos centrais do enfoque CTS é desenvolver a alfabetização científica dos estudantes, para que eles tenham condições de fazer o bom uso dos conhecimentos científicos no seu cotidiano, pois "existe ciência no laboratório e na rua, no telefone celular que não se larga e no adoçante que, com inocência, adicionamos ao suco na hora do lanche" (SELBACH, 2010, p. 41). Assim, o conhecimento científico deixa de ter um fim em si mesmo para ser relacionado aos contextos de vida real, sejam eles próximos ou distantes do estudante, buscando dar sentido aos questionamentos tratados em sala de aula.

O ensino de ciências com enfoque CTS pode ser abordado por meio de temas de relevância social, realização de atividades destinadas à resolução de problemas, confronto de diferentes pontos de vista, análise crítica de argumentos, discussão da 
validade das conclusões alcançadas e elaboração de novas questões. Em geral, os temas de relevância social apresentam um forte componente interdisciplinar, além de critérios que os caracterizam como um tema CTS: a) possibilita o estabelecimento de relações entre as implicações da ciência e/ou da tecnologia na sociedade; $b$ ) apresenta um significado real para o estudante de modo que seu envolvimento será significativo; c) é controverso, estimula o debate por existirem opiniões diferentes a seu respeito; e d) viabiliza a instituição de relações das pessoas com o mundo (SANTOS; SCHNETZLER, 2010; FOUREZ et al., 1997).

Para Gil-Pérez e Vilches (2006), a alfabetização científica é fundamental para: a) tornar a ciência acessível aos cidadãos em geral; b) reorientar o ensino de ciências também para futuros cientistas; c) modificar concepções errôneas da ciência frequentemente aceitas e difundidas; e d) tornar possível a aprendizagem significativa de conceitos. Romanatto e Viveiro apresentam ideias semelhantes e defendem que a alfabetização cientifica é uma das prioridades do ensino de ciências nos anos iniciais do ensino fundamental, pois "pode contribuir para uma leitura e interpretação de mundo que favoreça posicionamentos e tomadas de decisões, de modo crítico e criativo, em questões que envolvam nós, os outros e o ambiente" (2015, p. 9).

A alfabetização científica deve ser concebida pelos estudantes como um processo que articule o domínio do vocabulário, simbolismos, fatos, conceitos, princípios e procedimentos da Ciência; as características próprias do "fazer ciências"; as relações entre Ciência, Tecnologia, Sociedade e Ambiente e suas repercussões a fim de compreender os significados da linguagem científica, bem como interagir com o mundo em que vive (FOUREZ et al., 1997; SASSERON; CARVALHO 2011).

Na literatura, existem diferentes sugestões de classificação da alfabetização científica, como as de Shen (1975), Marco (2000) e Fourez et al. (1997), assim como as apresentadas nos trabalhos de Lorenzetti e Delizoicov (2001) e de Milaré, Richetti e Pinho-Alves (2009), que a identificam de quatro formas:

a) a alfabetização científica prática: busca contribuir para a apropriação de conhecimentos científicos e técnicos essenciais para a resolução de problemas básicos presentes no cotidiano. Essa alfabetização deve favorecer a interpretação de fenômenos presentes na vida diária, compreender instruções sobre o funcionamento de equipamentos domésticos e as necessidades humanas relacionadas à melhoria de condições de vida do ser humano, como alimentação e saúde.

b) a alfabetização científica cívica: tem como propósito favorecer o desenvolvimento de conhecimentos científicos que subsidiem a tomada de decisões, para que o cidadão possa ser mais participativo nos processos democráticos 
da sociedade, cada vez mais tecnológica, alertando-o inclusive para as questões relacionadas à ciência e aos problemas por ela provocados. Nessa perspectiva, "a alfabetização científica cívica poderá contribuir para minimizar a grande quantidade de superstições e crenças que permeiam a sociedade" (LORENZETTI; DELIZOICOV, 2001, p. 5).

c) a alfabetização científica cultural: é restrita aos indivíduos que desejam conhecer a ciência em profundidade e buscam conhecer os aspectos históricos e epistemológicos de sua constituição, bem como suas curiosidades. Segundo Shen, a alfabetização científica cultural "não resolve nenhum problema prático diretamente, mas favorece a abertura de caminhos para a ampliação entre as culturas científicas e humanísticas" (1975, p. 267).

d) a alfabetização científica econômica ou profissional: destina-se a incentivar a formação de profissionais para o trabalho científico, buscando promover e manter o crescimento econômico dos países (FOUREZ et al., 1997).

A escola exerce papel fundamental para a formação cidadã, mas a ela cabe apenas uma parte desse processo, que é desenvolvido e concluído nas diferentes instituições que compõem a sociedade (SANTOS; SCHNETZLER, 2010). Corroborando essa perspectiva, Lorenzetti e Delizoicov argumentam que, "se a escola não pode proporcionar todas as informações científicas que os cidadãos necessitam, deverá, ao longo da escolarização, propiciar iniciativas para que os alunos saibam como e onde buscar os conhecimentos que necessitam para a sua vida diária" (2001, p. 7).

O modo de ensinar e as estratégias metodológicas adotadas também constituem aspectos fundamentais para o êxito da alfabetização científica, e, para isso, os professores devem estar bem preparados para colocá-los em prática. Fourez et al. (1997) assinalam a importância de os componentes curriculares dos cursos de licenciatura contemplarem estudos sobre história da ciência, epistemologia, interdisciplinaridade, aspectos tecnológicos, aspectos sociais e conteúdos específicos. Em síntese:

Alguns pontos centrais, comuns entre as ideias de Alfabetização Científica apresentadas, podem ser destacados: a) As pessoas em geral devem possuir um mínimo de conhecimento científico; b) $\mathrm{O}$ ensino de Ciências deve ser diferente do ensino propedêutico, centrado em conteúdos que se encerram em si mesmos e c) Aspectos sociais e culturais devem ser considerados no Ensino (MILARÉ; RICHETTI; PINHO-ALVES, 2009, p. 167).

A adoção de temas voltados à abordagem das relações CTS nas aulas de ciências pode favorecer a concretização dessas ideias centrais, pois os conteúdos científicos são abordados de forma associada às questões da atualidade, mostrando aos alunos a importância de aprender ciências e contribuindo para o exercício das re- 
lações interdisciplinares. Nessa perspectiva, a alfabetização científica contribuirá para a formação de cidadãos que tenham condições de utilizar a ciência e a tecnologia em benefício próprio, da sociedade e do ambiente, abandonando a condição de mero espectador, para desenvolver e compreender os processos envolvidos.

\section{Dos fundamentos teóricos do ensino de ciências à inserção do enfoque CTS: 0 percurso de atividades no componente curricular}

O trabalho final produzido pelos licenciandos consistiu na elaboração de uma proposta metodológica para o ensino de ciências dos anos iniciais do ensino fundamental, orientada pelo enfoque CTS. Esse trabalho foi realizado em três turmas presenciais $^{3}$ do componente curricular Fundamentos teórico-metodológicos e prática escolar em ciências, no quarto período do curso de Pedagogia da UFJF. No segundo semestre de 2014, a atividade foi realizada em duas turmas, uma do curso diurno, com 30 licenciandos, e outra do curso noturno, com 40 licenciandos. $\mathrm{Na}$ terceira turma, com 35 licenciandos do curso noturno, as atividades aconteceram no primeiro semestre de 2017.

Apesar de as reflexões se direcionarem à análise dos trabalhos finais, cabe situar o contexto das atividades realizadas anteriormente. No curso de licenciatura em Pedagogia da UFJF, esse componente curricular é o único obrigatório destinado ao ensino de ciências, cuja ementa prevê o estudo de temas como a natureza do conhecimento científico, ciência, técnica e tecnologia, o saber popular e o saber científico, aspectos históricos e epistemológicos do ensino de ciências, contribuições e limites dos livros didáticos e recursos didáticos, atividades experimentais.

As atividades realizadas nas três turmas, nos dois semestres, seguiram a mesma estrutura. Inicialmente, foram abordados os fundamentos teóricos ${ }^{4}$ sobre 0 ensino de ciências, com o estudo sobre o que é ciência, a natureza do conhecimento científico e elementos da epistemologia da ciência. O papel do professor como mediador entre os saberes do senso comum e da ciência também foram discutidos.

A seguir, iniciamos o estudo e a discussão sobre o enfoque CTS e alguns dos recursos didáticos recomendados pela literatura para abordar CTS nas aulas de ciências. Os textos utilizados no componente curricular foram disponibilizados previamente para os licenciandos e, em cada aula, foram realizadas atividades em grupo, como produção de desenhos sobre a atividade científica, análise de trabalhos realizados no ensino de ciências dos anos iniciais do ensino fundamental publicadas nos anais do Encontro Nacional de Pesquisa em Educação em Ciências, debates sobre os temas abordados em sala a partir de questionamentos propostos pela professora formadora, priorizando o trabalho em grupos. Assim, o percurso 
de atividades foi direcionado para minimizar as discussões pouco representativas, fragmentadas e lineares da ciência, apontadas pela literatura como problemáticas na formação inicial do pedagogo.

Finalmente, os licenciandos receberam orientações para o trabalho final. Os requisitos obrigatórios envolveram a escolha de um tema CTS e, pelo menos, uma estratégia metodológica para elaborar as atividades da proposta, planejada para quatro aulas escolares. Os pressupostos teóricos e metodológicos estudados ao longo do semestre deveriam fundamentar os trabalhos das equipes, que foram avaliadas pela apresentação oral e pelo trabalho escrito. Na apresentação oral, os grupos discorreram sobre o tema e a justificativa da escolha, descreveram a sequência de atividades planejadas e, entre elas, escolheram e prepararam uma para os colegas vivenciarem. Foi disponibilizado um arquivo em Microsoft Word com orientações para a estrutura do trabalho escrito, a saber: um resumo com até 200 palavras, três palavras-chave, introdução, fundamentação teórica, descrição da metodologia, considerações do grupo e referências. A seguir, serão apresentados os trabalhos escritos e produzidos pelos licenciandos e algumas reflexões advindas dessas produções.

\section{Identificação e classificação dos temas das propostas metodológicas}

Foram apresentados 21 trabalhos, sendo 5 na turma do curso diurno e 8 na turma do curso noturno, ambas em 2014. Na turma do curso noturno, em 2017, foram produzidos 8 trabalhos. Para facilitar a identificação, as turmas serão denominadas, respectivamente, de turma 1 , turma 2 e turma 3.

Cinco propostas foram excluídas da análise, sendo uma da turma 1 e três da turma 2, porque os temas escolhidos não foram relacionados ${ }^{5}$ ao enfoque CTS, e uma proposta da turma 3 , porque a equipe não entregou o trabalho escrito. A análise dos 16 trabalhos restantes possibilitou reuni-los em quatro grupos temáticos, conforme exposto no Quadro 1: 
Quadro 1 - Classificação dos temas CTS nos trabalhos analisados

\begin{tabular}{|c|c|}
\hline \multicolumn{2}{|l|}{ Turma 1} \\
\hline Título & Classificação \\
\hline $\begin{array}{l}\text { Sequência didática sobre os tipos de cabelos: proposta com enfoque CTS para o } \\
\text { ensino fundamental }\end{array}$ & Saúde e estética \\
\hline Alimentação saudável & Saúde e alimentos \\
\hline Benefícios e malefícios das bebidas mais consumidas diariamente & Saúde e alimentos \\
\hline Água: conscientização & Meio ambiente \\
\hline \multicolumn{2}{|l|}{ Turma 2} \\
\hline Título & Classificação \\
\hline A seca no Brasil - experiência do solo engolidor de água & Meio ambiente \\
\hline A importância de uma água de qualidade & Meio ambiente \\
\hline A importância dos ecossistemas: CTSA, ecossistema, terrário & Meio ambiente \\
\hline Resgatando a infância através de brinquedos recicláveis & Meio ambiente \\
\hline A produção do papel e seus impactos ambientais & Meio ambiente \\
\hline \multicolumn{2}{|l|}{ Turma 3} \\
\hline Título & Classificação \\
\hline Práticas pedagógicas em CTS: alimentação saudável nos anos iniciais & Saúde e alimentos \\
\hline Educação alimentar: repensando nossas escolhas & Saúde e alimentos \\
\hline Como a água vira chuva? & Meio ambiente \\
\hline De onde vem e para onde vai o lixo da nossa casa? & Meio ambiente \\
\hline Do lixo para a mesa & Meio ambiente \\
\hline $\begin{array}{l}\text { Abordagem temática freireana e o ensino em ciência, tecnologia e sociedade: pro- } \\
\text { posta dos três momentos pedagógicos para o terceiro ano do ensino fundamental }\end{array}$ & Meio ambiente \\
\hline Poluição do ar & Meio ambiente \\
\hline
\end{tabular}

Fonte: elaboração da autora.

Os temas relacionados ao meio ambiente foram escolhidos por doze grupos, sendo quatro trabalhos sobre água, quatro sobre lixo, dois sobre poluição e um sobre ecossistema. Essa adesão evidencia a preocupação em formar cidadãos atentos aos impactos ambientais provocados pelo intenso desenvolvimento científico e tecnológico e, portanto, atuantes no seu meio social. Cinco trabalhos abordaram temáticas relacionadas à saúde, sendo quatro direcionados à alimentação saudável 
e um, à estética. Esse é um dos aspectos que refletem a influência cada vez maior da ciência e da tecnologia nos hábitos de consumo da sociedade.

\section{Análise dos temas: apropriações sobre o enfoque CTS}

Conforme discutido anteriormente, um tema CTS é caracterizado por se relacionar a situações vivenciadas ou conhecidas dos estudantes, oportunizando o envolvimento na discussão de forma significativa e o desenvolvimento da capacidade de tomada de decisão. Para analisar os trabalhos escritos quanto às apropriações dos grupos sobre os pressupostos do enfoque CTS, utilizaram-se os quatro elementos que caracterizam um tema CTS. Assim, buscou-se identificar, nos trabalhos escritos, pequenos trechos demonstrativos dessas apropriações, que serão apresentadas, a seguir, por grupos temáticos.

\section{Meio ambiente}

As quatro propostas sobre o tema "lixo" apresentaram justificativas fundamentadas em ideias relacionadas às implicações da ciência e/ou da tecnologia na sociedade, por exemplo: "a produção de resíduos também aumentou com o consumo de produtos descartáveis" e "desenvolver em sala de aula a inter-relação entre ciências, tecnologia e decisões, permitindo que os alunos consigam realizar uma maior reflexão acerca dos diversos problemas ocasionados pelo lixo". Esse é um tema carregado de significados reais para os estudantes, pois proporciona a autorreflexão sobre hábitos de consumo e suas próprias atitudes em relação ao lixo. As controvérsias em torno dos impactos ambientais e sociais provocados pelo descarte inadequado do lixo estimulam o debate e mostram a importância da atuação cidadã diante de problemas tão atuais e gerados pelos seres humanos.

O consumo da água, a falta de chuva e a consequente escassez de água nos reservatórios foram os aspectos privilegiados nos quatro trabalhos sobre o tema "água". As implicações da ciência e/ou da tecnologia foram claramente indicadas por ideias como: "além do uso excessivo da água, a poluição é fator determinante para que a água que utilizamos esteja cada vez pior"; "importância de uma água de qualidade para o consumo humano"; "a ciência, nessa aula, é caracterizada como prática social, pois a temática permite a participação ativa do estudante na sociedade"; e "o tema escolhido é CTS, à medida que a água envolve aspectos sociais e está relacionada à degradação ambiental". A ênfase na conscientização em prol do meio ambiente e do contexto de vida do estudante favorece o seu envolvimento nas atividades recomendadas, bem como oportuniza a ele o desenvolvimento de valores 
éticos, a compreensão e a reflexão sobre os fatores que contribuem para a escassez da água em nosso planeta.

Para o tema "poluição", foram propostos dois trabalhos, um direcionado para a poluição do ar e outro para os impactos ambientais da produção do papel. Ambos apresentaram justificativas relacionadas ao enfoque CTS, por exemplo: "As impurezas, ou seja, as substâncias que não fazem parte da constituição da atmosfera podem prejudicar os seres vivos, e as poluições geram desastres ambientais cada vez maiores, resultando em problemas ambientais em todo o planeta"; e "A produção do papel é uma atividade que possui elevados níveis de consumo de recursos e os impactos no meio ambiente são inevitáveis". Porém, avaliou-se que há aspectos pouco significativos para os estudantes desse nível de ensino, possivelmente pela escolha em abordar fontes de poluição atmosférica pouco conhecidas dos estudantes e o processo de produção de papel, que envolve processos químicos e físicos cuja explicação requer o uso da linguagem científica de forma muito específica.

Um trabalho foi dedicado às ações humanas que prejudicam os ecossistemas, cuja justificativa foi apresentada da seguinte forma: "Os ecossistemas e a diversidade biológica representam a riqueza natural do planeta. No entanto, estão desaparecendo numa velocidade impressionante, por ação do próprio ser humano". Essas ideias fomentam a discussão sobre a importância das relações entre os cidadãos e o meio ambiente em prol da preservação ambiental, tão importante para a qualidade de vida das pessoas.

\section{Saúde}

Os quatro trabalhos que abordaram o tema "alimentação saudável" apresentaram diferentes direcionamentos. Nessa proposta, o grupo associou o tema às discussões sobre os padrões corporais idealizados pela sociedade e doenças como bulimia, anorexia e obesidade. Em "Os benefícios e malefícios das bebidas mais consumidas diariamente", o grupo privilegiou a discussão sobre os refrigerantes, acrescentando também a importância de beber água e os benefícios e malefícios dos sucos de fruta naturais e industrializados. No terceiro trabalho, intitulado "Práticas pedagógicas em CTS: alimentação saudável nos anos iniciais”, a discussão ficou em torno de alimentos industrializados e alimentos saudáveis; no quarto trabalho, "Educação alimentar: repensando nossas escolhas", o grupo direcionou a proposta para a discussão sobre dieta balanceada, chamando a atenção para a quantidade de açúcar presente nos alimentos que os estudantes dos anos iniciais consomem.

As justificativas dos quatro grupos para os temas escolhidos apresentam claramente as implicações da ciência e da tecnologia na sociedade, porque apresentam 
um significado social e mobilizam diferentes opiniões, pois os hábitos alimentares dos estudantes nem sempre são iguais. A discussão sobre saúde e alimentação é um convite à reflexão por trazer à tona a percepção dos alunos sobre os alimentos que consomem, podendo ou não assumir o compromisso de mudar seus hábitos alimentares.

Um único trabalho foi dedicado às relações da saúde com estética e foi direcionado para os diferentes tipos de cabelos e os produtos para tratamento ou modificação de sua estrutura. Alguns aspectos relacionados ao autocuidado foram indicados, por exemplo: "mostrar que cada cabelo tem uma composição diferente e, por isso, deve ser valorizado" e "explicar por que os produtos capilares utilizados pelos adultos não são recomendados para crianças". Essas ideias têm um significado social para os estudantes, uma vez que, além de abordar as diferenças corporais, possibilita ampliar o debate sobre a diversidade étnico-racial.

\section{As relações entre 0 enfoque CTS e o ensino de ciências nas sequências de atividades}

No trabalho final, as equipes deveriam articular o tema às interfaces entre ciência, tecnologia e sociedade e aos conteúdos de ciências por meio de diferentes estratégias metodológicas adequadas aos anos iniciais do ensino fundamental. Nesta seção, a análise será direcionada para o alcance dessas articulações.

\section{Meio ambiente}

Entre os quatro trabalhos com a temática "meio ambiente", três sugeriram questionamentos para conhecer o que os alunos já sabiam sobre lixo e meio ambiente para iniciar a sequência de aulas. Um trabalho propôs iniciar com a construção de um lago poluído em sala de aula, utilizando um tecido azul para simular a água do lago e algumas embalagens vazias para representar o lixo. A partir dessa simulação, seriam feitos questionamentos sobre o ambiente e os objetos presentes nele, seguidos de uma pescaria para limpar o lago.

Nesses quatro trabalhos, as atividades envolveram rodas de conversa com problematizações complementares, contação de histórias, exibição de vídeos de curta duração, leitura de textos informativos extraídos de sítios da internet e algumas aulas expositivas.

Para finalizar a sequência de aulas, dois grupos sugeriram a construção de brinquedos e jogos com os materiais recicláveis que os alunos trouxeram de casa. 
Um grupo escolheu a montagem de uma composteira doméstica a partir de garrafas PET; em outro, os alunos receberiam uma cópia do livro Tô saindo pra pescar, de Denise Rochadel, com os balões de diálogo em branco, para eles produzirem suas próprias histórias.

Os conteúdos de ciências versaram sobre os principais materiais que compõem o lixo e a diferença entre o lixo orgânico e o reciclável. As quatro propostas temáticas ilustraram de forma clara as implicações da ciência e da tecnologia no meio ambiente e, consequentemente, nos hábitos da sociedade.

Para a temática água, os grupos sugeriram iniciar as aulas com rodas de conversa sobre "como a água vira chuva", "poluição das águas", "desinfecção da água" e "a falta de chuva na cidade de Juiz de Fora". Na sequência, foram indicadas outras atividades, como experimentação, discussões sobre novos questionamentos, análise da música "Planeta Água", elaboração de desenhos em cartazes, visita à Usina Hidrelétrica de Marmelos e exibição de vídeos e reportagens sobre a seca na região de Juiz de Fora.

As atividades finais envolveram: a produção de um terrário; a confecção de cartazes para uma campanha sobre o consumo consciente da água, para serem expostos nos locais da escola em que as pessoas utilizam água; debates sobre a seca a partir das reportagens assistidas pelos alunos; e a construção de um microscópio com materiais caseiros. Avalia-se que, nesses quatro trabalhos, as equipes planejaram atividades de fácil realização em sala de aula e destacaram as interfaces CTS e a presença dos conteúdos de ciências.

A roda de conversa também foi sugerida para iniciar as atividades sobre a poluição do ar e os impactos ambientais da produção de papel. As atividades sugeridas na sequência foram exibição de vídeos, pesquisa na internet sobre sustentabilidade ambiental, atividades experimentais e aulas expositivas. $\mathrm{O}$ trabalho sobre poluição do ar privilegiou atividades experimentais possíveis de serem realizadas pelos estudantes, enquanto a proposta sobre a produção de papel descreveu o uso de imagens e vídeos para abordar o ciclo produtivo do papel e a reciclagem. Em relação a este último trabalho, avaliou-se que as atividades ficaram mais centralizadas no professor do que nos alunos, e isso pode estar associado à complexidade do tema escolhido pela equipe.

No trabalho sobre a importância dos ecossistemas, as atividades foram concentradas em torno da construção de um terrário. A equipe sugeriu uma lista de conteúdos de ciências que poderiam ser abordados, como composição do ar e da água, importância do ar e da água para os seres vivos, fotossíntese, vegetais, animais, energia e nutrição. As articulações com o enfoque CTS foram evidenciadas nas discussões sobre o filme Vida de inseto e um vídeo sobre o ciclo da água, ou seja, 
foram desenvolvidas ao longo do trabalho. Observou-se que essa equipe privilegiou os conteúdos científicos em torno da construção e do funcionamento do terrário em detrimento das interfaces CTS.

\section{Saúde}

A roda de conversa e o levantamento dos conhecimentos dos alunos por meio de questionamentos foram o ponto de partida das quatro propostas sobre alimentação saudável. As estratégias adotadas para dar continuidade às aulas envolveram debates sobre questões controversas relacionadas a alimentos e bebidas consumidos pelos estudantes, bem como sobre suas preferências alimentares. Além do debate, algumas equipes indicaram a realização de um diário alimentar, com 0 registro dos alimentos consumidos pelos estudantes durante um final de semana, a utilização de aplicativos de celular e outros disponíveis em sites da internet. Também foram indicadas, nos quatro trabalhos, aulas expositivas para abordar a pirâmide alimentar, os grupos de alimentos, os nutrientes dos alimentos, a quantidade de açúcar presente nos alimentos industrializados e a importância da água para a saúde. Uma das proposta direcionou as atividades finais para a confecção de cartazes, outra para experimentação e as demais para jogos educativos.

Cabe destacar que, nos últimos anos, o aumento no consumo de alimentos ultraprocessados foi proporcional ao aumento da oferta e variedade desses produtos, cujas implicações à saúde têm sido relatadas por médicos e nutricionistas. No âmbito dos estudantes dos anos iniciais do ensino fundamental, o elevado consumo de guloseimas é, muitas vezes, motivado pelas propagandas de TV e pelas embalagens desses produtos, geralmente chamativas. Esses aspectos suscitam discussões em torno do enfoque CTS e foram contemplados nos quatro trabalhos.

A roda de conversa também foi escolhida para iniciar a discussão sobre os tipos de cabelo. As atividades seguintes envolveram a observação de diferentes fios de cabelo no microscópio, a leitura do texto "Cabeleira colorida", da revista Ciência Hoje das Crianças, a realização de entrevistas para conhecer os tipos de cabelos de outras pessoas e a exposição de um vídeo sobre as consequências do uso inadequado de um produto capilar. Essas atividades foram alternadas com momentos de exposição sobre composição e tipos de cabelo, produtos de higiene, produtos que alteram a estrutura dos fios de cabelo, formol e contribuições da ciência para a indústria de cosméticos. Para finalizar a proposta, foram sugeridos um debate sobre os prós e os contras do uso de produtos químicos nos cabelos e a confecção de cartazes.

Nesses cinco trabalhos sobre saúde, os planejamentos demonstraram o comprometimento dos grupos em articular o enfoque CTS e o ensino de ciências para 
abordar os temas escolhidos. As estratégias de ensino foram protagonistas e estruturadoras da sequência de aulas, nas quais se buscou descentralizar as informações do professor, favorecendo o protagonismo dos estudantes em buscar e compartilhar informações com os demais colegas e com o próprio professor.

Cabe destacar a presença das aulas expositivas ao longo dos dezesseis trabalhos e, a esse respeito, pode-se inferir que houve preocupação em não perder o conteúdo científico de vista, ao mesmo tempo em que as atividades ofereceram momentos de incentivo ao diálogo e de ludicidade associados à aprendizagem. Essa inferência tem como pressuposto os diálogos estabelecidos ao longo do componente curricular acerca da importância de ensinar ciências em torno de situações significativas ao estudante, buscando se distanciar das visões equivocadas e/ou distorcidas sobre a ciência e a atividade científica. Os vídeos escolhidos pelas equipes foram, em geral, desenhos animados e filmes cujos personagens são conhecidos dos estudantes e vídeos de animação com teor educativo.

\section{Possibilidades para a alfabetização científica nos trabalhos analisados}

A adoção de temas CTS no ensino de ciências pressupõe o favorecimento de uma (ou mais) finalidade da alfabetização científica: prática; cívica; cultural; e econômica ou profissional. Considerando que a alfabetização científica é um dos objetivos do enfoque CTS, os trabalhos finais também foram analisados quanto às perspectivas para as finalidades da alfabetização científica. No Quadro 2, apresenta-se cada finalidade e a respectiva descrição, utilizadas para essa análise.

Quadro 2 - Finalidades da alfabetização científica utilizadas para analisar os trabalhos finais

\begin{tabular}{|l|l|}
\hline \multicolumn{1}{|c|}{ Finalidade } & \multicolumn{1}{c|}{ Descrição } \\
\hline Prática & $\begin{array}{l}\text { Temas ou exemplos que permitem a interpretação baseada em conhecimentos cientí- } \\
\text { ficos e técnicos, como o funcionamento de artefatos tecnológicos, a ação de produtos } \\
\text { e a explicação de fenômenos naturais. }\end{array}$ \\
\hline Cívica & $\begin{array}{l}\text { Temas que subsidiem o estudante para tomar alguma decisão, visando sua participa- } \\
\text { ção mais efetiva na sociedade. }\end{array}$ \\
\hline Cultural & $\begin{array}{l}\text { Aspectos relacionados à natureza e ao desenvolvimento da ciência e da tecnologia, } \\
\text { como histórias e curiosidades. }\end{array}$ \\
\hline $\begin{array}{l}\text { Econômica ou } \\
\text { profissional }\end{array}$ & $\begin{array}{l}\text { Temas e exemplos que mostrem como os conhecimentos científicos são utilizados, } \\
\text { suas finalidades econômicas e/ou formação de profissionais. }\end{array}$ \\
\hline
\end{tabular}

Fonte: elaboração da autora. 
Nos dezesseis trabalhos, foram localizados trechos característicos dessas quatro finalidades, mas a frequência nas categorias temáticas foi diferenciada, conforme apresentado a seguir.

\section{Meio ambiente}

Nos quatro trabalhos que abordaram a temática "lixo", as finalidades prática e cívica da alfabetização científica foram predominantes. Abordagens relacionadas a identificação dos diferentes materiais que são jogados no lixo, tempo de decomposição desses materiais no ambiente, reciclagem, reutilização e reaproveitamento são características da finalidade prática. Os questionamentos utilizados em rodas de conversa e debates são próprios da finalidade cívica, por exemplo: "como o lixo afeta o nosso meio ambiente" e "como podemos separar os lixos de forma que seu descarte seja menos prejudicial ao meio ambiente?". Os argumentos econômicos foram relacionados ao beneficiamento do lixo reciclável, à redução do consumo e às cooperativas que fazem o beneficiamento do lixo reciclável. Nesses trabalhos, não foram identificados argumentos em prol da finalidade cultural da alfabetização científica.

Para o tema "água", foram identificadas possibilidades para as quatro finalidades da alfabetização científica, distribuídas de formas distintas nos quatro trabalhos. O caráter prático foi identificado em algumas atividades, por exemplo: na construção do terrário e na posterior observação para compreender como ocorre o ciclo da água, na construção de um filtro caseiro para remover partículas sólidas da água, na compreensão dos benefícios e dos malefícios do cloro presente na água tratada para a saúde e em um experimento destinado a mostrar como a água é absorvida por diferentes tipos de solo.

Elementos da finalidade cívica estão muito presentes nas quatro propostas por meio de objetivos e questionamentos destinados a: "oferecer uma compreensão abrangente da utilização da água e da importância de se repensar essa utilização, não somente nas atividades domésticas, mas também no consumo industrial"; além disso, "a seca não se resume à falta de água, pois faltam soluções para resolver a sua má distribuição e as dificuldades de seu aproveitamento".

Argumentos econômicos relacionados ao consumo consciente de água também foram abordados, dentre os quais, destaca-se a realização de "uma campanha na escola para preservação da água, espalhando cartazes com alertas sobre o consumo de água e dicas para economizá-la".

Alguns desses trabalhos indicaram argumentos culturais: "desmistificação de visões distorcidas que os alunos criaram sobre a ciência, aproximando seu cotidiano 
dos ensinamentos construídos em sala de aula"; “o uso da água obedece a questões temporais e espaciais". Além disso, foi proposta a construção de um microscópio caseiro, que aumenta a imagem até 1.000 vezes, para observar a presença de micro-organismos em uma amostra de água contaminada.

\section{Saúde}

Na proposta sobre os tipos de cabelos, há um forte componente relacionado à tomada de decisões devido à ênfase sobre a importância do uso adequado de produtos para alisamento ou coloração. Essa ideia foi associada ao aprendizado sobre os diferentes tipos de cabelo, suas características e os resultados do uso desses produtos: "[...] serão diferentes uns dos outros e, muitas vezes, o resultado não é o esperado, trazendo graves problemas". Assim, considera-se que, nesse trabalho, existe a predominância da finalidade cívica da alfabetização científica. A finalidade prática também foi identificada nas atividades de observação de diferentes fios de cabelo no microscópio e na aula expositiva na qual são abordados os benefícios dos produtos capilares.

A importância de conhecer alimentos e bebidas consumidos diariamente, as implicações na saúde do consumo excessivo de alimentos e bebidas industrializados e os efeitos do excesso de açúcar estão presentes nas quatro propostas sobre saúde e alimentação e se referem à finalidade prática da alfabetização científica. Nesses trabalhos, a ênfase dada à importância da alimentação saudável nas diferentes atividades suscita a discussão de ideias relacionadas à finalidade cívica da alfabetização científica, por exemplo: "alertar os alunos sobre a influência que a sociedade tem na forma como nos alimentamos"; "fazer com que os alunos reflitam sobre sua alimentação e conscientizá-los a respeito de uma alimentação saudável"; e "ao tratar de um tema dessa relevância, estaremos mobilizando não somente os alunos, mas também seus familiares, conscientizando-os para uma alimentação saudável e qualidade de vida”.

Em um dos trabalhos, há possibilidades para a finalidade econômica ou profissional na atividade destinada ao entendimento sobre os custos de uma alimentação saudável, na qual a equipe propôs a construção de um mercadinho com embalagens e fotos de alimentos, em que os alunos receberiam quantidades diferentes de dinheiro fictício para fazer compras de acordo com seus hábitos alimentares. Nesse mesmo trabalho, há uma discussão sobre a exploração de mão de obra na produção de alimentos, na qual o professor mostra uma lista de empresas que fazem uso do trabalho infantil ou têm seus lucros aumentados por explorarem a força de traba- 
lho. Nos cinco trabalhos sobre saúde, não foram localizadas ideias relacionadas à finalidade cultural.

Nos dois trabalhos sobre poluição, a finalidade prática da alfabetização científica refere-se a "compreender o processo de produção do papel" e "disseminar o conhecimento sobre os efeitos negativos da poluição atmosférica". A finalidade cívica foi direcionada à discussão sobre a sustentabilidade ambiental e os danos ao meio ambiente provocados pela indústria de papel e celulose. Os argumentos que caracterizam a finalidade econômica ou profissional foram apresentados de forma ampla e referem-se à discussão sobre "a importância econômica da indústria de papel e celulose" e a "utilização dos recursos naturais de forma sustentável". Nesse tema, não foi indicada finalidade cultural da alfabetização científica.

Na proposta sobre os ecossistemas, a ênfase dada aos conteúdos de ciências relacionados ao terrário restringiu a abordagem das finalidades prática e cívica da alfabetização científica, identificadas nos trechos: "para que as crianças descubram o mundo ao seu redor, o ideal é que o primeiro contato com os conceitos naturais aconteça de maneira divertida, investigativa e planejada"; "esta proposta teve como foco o ecossistema para tratar de forma ampla assuntos CTSA [Ciência, Tecnologia, Sociedade e Ambiente], de preservação ambiental, partindo do princípio que é preciso conhecer para despertar o desejo de preservação". Em síntese, o Quadro 3 apresenta a distribuição das finalidades da alfabetização científica em cada um dos trabalhos analisados. 
Quadro 3 - Finalidades da alfabetização científica identificadas nos trabalhos finais

\begin{tabular}{|l|c|c|c|c|}
\hline \multirow{2}{*}{\multicolumn{1}{|c|}{ Título }} & \multicolumn{2}{c|}{ Finalidades da alfabetização científica } \\
\cline { 2 - 5 } & Prática & Cívica & Cultural & $\begin{array}{c}\text { Econômica ou } \\
\text { profissional }\end{array}$ \\
\hline Resgatando a infância através de brinquedos recicláveis & $\mathrm{X}$ & $\mathrm{X}$ & & $\mathrm{X}$ \\
\hline De onde vem e para onde vai o lixo da nossa casa? & $\mathrm{X}$ & $\mathrm{X}$ & & $\mathrm{X}$ \\
\hline Do lixo para a mesa & $\mathrm{X}$ & $\mathrm{X}$ & & $\mathrm{X}$ \\
\hline $\begin{array}{l}\text { Abordagem temática freireana e o ensino em ciência, tecno- } \\
\text { logia e sociedade: proposta dos três momentos pedagógi- } \\
\text { cos para o terceiro ano do ensino fundamental }\end{array}$ & $\mathrm{X}$ & $\mathrm{X}$ & & \\
\hline Como a água vira chuva? & $\mathrm{X}$ & $\mathrm{X}$ & $\mathrm{X}$ & $\mathrm{X}$ \\
\hline Água: conscientização & $\mathrm{X}$ & $\mathrm{X}$ & $\mathrm{X}$ & $\mathrm{X}$ \\
\hline A importância de uma água de qualidade & $\mathrm{X}$ & $\mathrm{X}$ & $\mathrm{X}$ & \\
\hline A seca no Brasil - experiência do solo engolidor de água & $\mathrm{X}$ & $\mathrm{X}$ & & $\mathrm{X}$ \\
\hline A produção do papel e seus impactos ambientais & $\mathrm{X}$ & $\mathrm{X}$ & & $\mathrm{X}$ \\
\hline Poluição do ar & $\mathrm{X}$ & $\mathrm{X}$ & & $\mathrm{X}$ \\
\hline $\begin{array}{l}\text { A importância dos ecossistemas: CTSA, ecossistema, } \\
\text { terrário }\end{array}$ & $\mathrm{X}$ & $\mathrm{X}$ & & \\
\hline $\begin{array}{l}\text { Sequência didática sobre os tipos de cabelos: proposta com } \\
\text { enfoque CTS para o ensino fundamental }\end{array}$ & $\mathrm{X}$ & $\mathrm{X}$ & $\mathrm{X}$ & \\
\hline Alimentação saudável & $\mathrm{X}$ & $\mathrm{X}$ & $\mathrm{X}$ & \\
\hline $\begin{array}{l}\text { Benefícios e malefícios das bebidas mais consumidas } \\
\text { diariamente }\end{array}$ & $\mathrm{X}$ & $\mathrm{X}$ & & \\
\hline $\begin{array}{l}\text { Práticas pedagógicas em CTS: alimentação saudável nos } \\
\text { anos iniciais }\end{array}$ & $\mathrm{X}$ & $\mathrm{X}$ & & \\
\hline Educação alimentar: repensando nossas escolhas & $\mathrm{X}$ & $\mathrm{X}$ & & \\
\hline
\end{tabular}

Fonte: elaboração da autora.

Os temas escolhidos pelos grupos mostraram-se adequados ao desenvolvimento da alfabetização científica, considerando suas principais finalidades. 


\section{Algumas considerações sobre o alcance do enfoque CTS na formação inicial do pedagogo para pensar as ciências dos anos iniciais do ensino fundamental}

Muitos professores acreditam que, para ensinar ciências, basta transmitir conhecimentos prontos, da forma como são organizados e apresentados nos livros didáticos. Essa concepção interfere na forma como o professor elabora e desenvolve as atividades com seus alunos. Além disso, a atuação profissional é influenciada pela visão que o próprio docente possui sobre o que é ciência e sobre a atividade científica, razão pela qual essas concepções precisam ser problematizadas na formação inicial.

Para minimizar a carência de discussões dos aspectos práticos constatados nos estudos de Gatti (2014) e Gatti e Nunes (2009), propôs-se aos licenciandos em Pedagogia a elaboração de propostas metodológicas para o ensino de ciências dos anos iniciais do ensino fundamental. O planejamento e a realização de uma atividade na data de apresentação dos trabalhos para os colegas de turma vivenciarem trouxeram à tona discussões sobre as dificuldades encontradas em "tirar a proposta do papel" e construir os materiais necessários à sua realização no momento da apresentação. Durante a execução das atividades, alguns trabalhos apresentaram problemas de clareza para o entendimento de regras e procedimentos, além de pequenas falhas nos materiais produzidos. A vivência e a realização das atividades propostas pelos colegas de turma constituíram um ensaio sobre a prática, favorecendo a apropriação e a construção, tanto coletiva como individual, dos conhecimentos científicos.

Para Bazzo, "as avaliações da ciência e da tecnologia e de suas repercussões na sociedade precisam seguramente tomar rumos mais claros e intensos nas atividades de todas as escolas" (2010, p. 103). É possível aproximar essa assertiva em defesa da presença dessas discussões nos cursos de formação inicial de professores, porque são fundamentais para enfatizar aos licenciandos a articulação entre as interfaces CTS e os conhecimentos científicos.

Considera-se que o alcance dessa proposta ainda é insuficiente diante das limitações relacionadas à abstração dos conteúdos científicos e da grande rejeição a eles demonstrada por alguns licenciandos. Mesmo assim, e diante da reduzida carga horária destinada às ciências no curso de Pedagogia, avalia-se que é uma iniciativa a ser propagada, pois se mostrou exitosa nas três turmas participantes. Se essas discussões não são abordadas na formação inicial, dificilmente o docente recém-formado terá condições de inserir em sua prática docente temas de relevância social e articulá-los aos conteúdos de ciências. 
É importante que, durante a formação inicial nos cursos de Pedagogia, os docentes formadores dediquem esforços para incentivar os licenciandos a estruturarem suas ideias e, acima de tudo, estarem dispostos a aprender novas estratégias de ensino e a exercitá-las em sala de aula. Torna-se um desafio aos docentes formadores proporcionar discussões sobre o ensino de ciências nos anos iniciais do ensino fundamental sem, contudo, alimentar ainda mais as raízes dos problemas apontados.

Compreender a relação entre o desenvolvimento da ciência e da tecnologia, bem como o respectivo impacto na vida dos cidadãos, provê autonomia para que o sujeito possa mobilizar esses conhecimentos tanto em ambientes de ensino formal como nos demais contextos.

\section{Notas}

1 O enfoque CTS pressupõe trazer a discussão dos aspectos que envolvem e inter-relacionam ciência, tecnologia e sociedade para o contexto educacional. No presente trabalho, essa discussão é abordada no ensino de graduação.

2 No texto da BNCC, consta a expressão letramento científico, que será denominada alfabetização científica ao longo deste trabalho.

3 Na UFJF, o curso de Pedagogia - licenciatura é oferecido nas modalidades presencial e a distância. Nos semestres em que lecionei o componente curricular na modalidade presencial, outro docente era responsável pelo componente curricular na modalidade a distância.

4 Os textos utilizados no estudo dos fundamentos teóricos foram: Cachapuz et al. (2005); Delizoicov, Angotti e Pernambuco (2011); Lorenzetti e Delizoicov (2001); Romanatto e Viveiro (2015); Santos e Mortimer (2002); Santos e Schnetzler (2010).

5 Os temas foram: Órgãos dos sentidos: visão; O ar tem peso?; Sistema solar; A produção de alimentos e a poluição do solo; e Higiene pessoal e saúde, sendo que este último foi apresentado oralmente e o trabalho escrito não foi entregue.

\section{Referências}

BAZZO, Walter A. Ciência, tecnologia e sociedade: e o contexto da educação tecnológica. 2. ed. rev. e atual. Florianópolis: Editora da UFSC, 2010.

BRASIL. Ministério da Educação. Secretaria de Educação Fundamental. Parâmetros Curriculares Nacionais: Ciências Naturais ( $1^{\mathrm{a}}$ a $4^{\mathrm{a}}$ série). Brasília: MEC/SEF, 1997.

Ministério da Educação. Resolução CNE/CP 1, de 15 de maio de 2006. Brasília: MEC, 2006. Disponível em: <http://portal.mec.gov.br/cne/arquivos/pdf/rcp01_06.pdf>. Acesso em: 29 jan. 2018.

. Ministério da Educação. Secretaria de Educação Básica. Base Nacional Comum Curricular: educação é a base. Brasília: MEC/SEB, 2017.

CACHAPUZ, Antonio et al. Superação das visões deformadas da ciência e da tecnologia: um requisito essencial para a renovação da educação científica. In: CACHAPUZ, A. et al. (Org.). A necessária renovação do ensino das ciências. São Paulo: Cortez, 2005. p. 37-70. 
CHRISPINO, Alvaro. Introdução aos enfoques CTS - ciência, tecnologia e sociedade - na educação e no ensino. Madrid, Espanha: Organização dos Estados Ibero-americanos, 2017.

DELIZOICOV, Demétrio; ANGOTTI, José A.; PERNAMBUCO, Marta M. Ensino de ciências: fundamentos e métodos. 4. ed. São Paulo: Cortez, 2011.

FOUREZ, Gerad et al. Alfabetización Científica y Tecnológica. Acerca de las finalidades de la enseñanza de las ciencias. Tradução de Elsa Gómez de Sarría. Buenos Aires: Ediciones Colihue, 1997.

GATTI, Bernardete A. A formação inicial de professores para a educação básica: as licenciaturas. Revista USP, São Paulo, n. 100, p. 33-46, 2014.

GATTI, Bernardete A.; NUNES, Marina M. R. Formação de professores para o ensino fundamental: estudo de currículos das licenciaturas em Pedagogia, Língua Portuguesa, Matemática e Ciências Biológicas. Textos FCC, São Paulo, v. 29, 2009.

GIL-PÉREZ, Daniel; VILCHES, Amparo. Educación Ciudadana y Alfabetización Científica: Mitos y Realidades. Revista Iberoamericana de Educación, Madrid, n. 42, p. 31-53, 2006.

LIMA, Maria Emília C. C.; MAUÉS, Ely. Uma releitura do papel da professora das séries iniciais no desenvolvimento e aprendizagem de ciências das crianças. Ensaio: Pesquisa em Educação em Ciências, Belo Horizonte, v. 8, n. 2, p. 161-175, 2006.

LORENZETTI, Leonir; DELIZOICOV, Demétrio. Alfabetização científica no contexto das séries iniciais. Ensaio: Pesquisa em Educação em Ciências, Belo Horizonte, v. 3, n. 1, p. 37-50, jun. 2001.

MALDANER, Otavio A.; NONENMACHER, Sandra E. B.; SANDRI, Vanessa. Ciências na educação fundamental: espaço um pouco esquecido na formação de professores. Acta Scientiae, Canoas, v. 12, n. 1, p. 112-122, jan./jun. 2010.

MARCO, Berta. La alfabetización científica. In: PERALES, Francisco J.; CANAL, Pedro. Didáctica de las Ciências Experimentales. Alcoy: Marfil, 2000. p. 141-164.

MILARÉ, Tathiane; RICHETTI, Graziela. P.; PINHO-ALVES, José. Alfabetização científica no ensino de Química: uma análise dos temas da seção "Química e Sociedade” da revista Química Nova na Escola. Química Nova na Escola, São Paulo, v. 31, n. 3, p. 165-171, ago. 2009.

ROMANATTO, Mauro C.; VIVEIRO, Alessandra A. Alfabetização científica: um direito de aprendizagem. In: BRASIL. Secretaria de Educação Básica. Diretoria de apoio à gestão educacional. Pacto Nacional pela Alfabetização na idade certa. Ciências da Natureza no ciclo de alfabetização. Brasília: MEC/SEB, 2015. Caderno 08. p. 9-18.

ROSA, Cleci T. Werner; PEREZ, Carlos A. S.; DRUM, Carla. Ensino de física nas séries iniciais: concepções da prática docente. Investigações em Ensino de Ciências, Porto Alegre, v. 12, n. 3, p. 357-368, 2007.

SANTOS, Wildson L. P.; MORTIMER, Eduardo F. Uma análise de pressupostos teóricos da abordagem CTS (Ciência-Tecnologia-Sociedade) no contexto da educação brasileira. Ensaio: Pesquisa em Educação em Ciências, Belo Horizonte, v. 2, n. 2, p. 133-162, 2002.

SANTOS, Wildson L. P.; SCHNETZLER, Roseli. Educação em Química: compromisso com a cidadania. 4. ed. rev. atual. Ijuí: Unijuí, 2010. 
SASSERON, Lúcia H.; CARVALHO Anna M. P. Alfabetização científica: uma revisão bibliográfica. Investigações em Ensino de Ciências, Porto Alegre, v. 16, n. 1, p. 59-77, 2011.

SELBACH, Simone (Sup. geral). Ciências e Didática. Petrópolis: Vozes, 2010. (Coleção Como Bem Ensinar).

SHEN, Benjamin S. P. Science Literacy. American Scientist, Carolina do Norte, v. 63, n. 3, p. 265-268, May/June 1975. 